\title{
Analyses and Forecasts of a Tornadic Supercell Outbreak Using a 3DVAR System Ensemble
}

\author{
Zhaorong ZHUANG ${ }^{* 1,2}$, Nusrat YUSSOUF ${ }^{1,3}$, and Jidong GAO $^{3}$ \\ ${ }^{1}$ Cooperative Institute for Mesoscale Meteorological Studies, University of Oklahoma, Norman, OK 73072, USA \\ ${ }^{2}$ Center of Numerical Weather Prediction, National Meteorological Center, China Meteorological Administration, Beijing 100081 \\ ${ }^{3}$ NOAA/National Severe Storms Laboratory, Norman, OK 73072, USA
}

(Received 27 March 2015; revised 21 September 2015; accepted 29 September 2015)

\begin{abstract}
As part of NOAA's "Warn-On-Forecast" initiative, a convective-scale data assimilation and prediction system was developed using the WRF-ARW model and ARPS 3DVAR data assimilation technique. The system was then evaluated using retrospective short-range ensemble analyses and probabilistic forecasts of the tornadic supercell outbreak event that occurred on 24 May 2011 in Oklahoma, USA. A 36-member multi-physics ensemble system provided the initial and boundary conditions for a 3-km convective-scale ensemble system. Radial velocity and reflectivity observations from four WSR-88Ds were assimilated into the ensemble using the ARPS 3DVAR technique. Five data assimilation and forecast experiments were conducted to evaluate the sensitivity of the system to data assimilation frequencies, in-cloud temperature adjustment schemes, and fixed- and mixed-microphysics ensembles. The results indicated that the experiment with 5-min assimilation frequency quickly built up the storm and produced a more accurate analysis compared with the 10-min assimilation frequency experiment. The predicted vertical vorticity from the moist-adiabatic in-cloud temperature adjustment scheme was larger in magnitude than that from the latent heat scheme. Cycled data assimilation yielded good forecasts, where the ensemble probability of high vertical vorticity matched reasonably well with the observed tornado damage path. Overall, the results of the study suggest that the 3DVAR analysis and forecast system can provide reasonable forecasts of tornadic supercell storms.
\end{abstract}

Key words: ensemble 3DVAR analysis, radar data assimilation, probabilistic forecast, supercell storm

Citation: Zhuang, Z. R., N. Yussouf, and J. D. Gao, 2016: Analyses and forecasts of a tornadic supercell outbreak using a 3DVAR system ensemble. Adv. Atmos. Sci., 33(5), 544-558, doi: 10.1007/s00376-015-5072-0.

\section{Introduction}

Accurate convective-scale forecasts of severe weather events like tornadoes, hailstorms, flash floods, and damaging windstorms are crucial to reduce the loss of lives, injuries and economic cost. However, there are many challenges in accurately forecasting high impact weather events, partly due to their small spatial and temporal scales, inherent nonlinearity of the dynamics and physics, limitations in weather forecast models and assimilation methods, and incomplete observation coverage (e.g., Stensrud et al., 2009; Xue et al., 2011; Snook et al., 2012). Nevertheless, with the rapid increase in computational power, progress has been made in the past decade in assimilating Doppler radar and other available observations of the ongoing convection in convectivescale NWP models with the goal to improve forecasts of severe thunderstorm events (e.g., Kain et al., 2010; Clark et al., 2012a). Due to the high sensitivity of convective-scale forecasts to both the storm environment and internal storm

\footnotetext{
* Corresponding author: Zhaorong ZHUANG

Email: zhuangzr@cams.cma.gov.cn
}

processes (e.g., Elmore et al., 2002; Gilmore et al., 2004; Snook and Xue, 2008), uncertainties associated with highimpact weather are large. Ensemble-based forecasting is currently among the most promising techniques for the purpose of better assessing uncertainty on the convective scale, and enabling probabilistic forecast guidance that can be made available to the public (Stensrud et al., 2009, 2013). With the advent of the "Warn-on-Forecast" (Stensrud et al., 2009, 2013) research and development project, which envisions a numerical model-based probabilistic convective-scale analysis and forecast system to support warning operations within the NOAA, the time is right to extensively explore ensemble data assimilation and forecasting for severe weather events.

The promising data assimilation approaches for convectivescale forecasting are the ensemble Kalman filter (EnKF) (Snyder and Zhang, 2003; Zhang et al., 2004; Dowell et al., 2004; Tong and Xue, 2005; Aksoy et al., 2009; Yussouf et al., 2013a; Wheatley et al., 2014) and localized ensemble transfer Kalman filter method (Lange and Craig, 2014; Thompson et al., 2015). However, a limitation of the convective-scale EnKF based approach is the rapid error growth in forecasts due to the lack of balance in the model dynamics (Lange and 
Craig, 2014). The 3D variational data assimilation scheme (3DVAR) can improve the balance among model variables by using weak constraints in the cost function (Gao et al., 1999, 2002, 2004; Hu et al., 2006a, b; Stensrud and Gao, 2010; Ge et al., 2013a, b). More advanced techniques, such as the 4D variational method (4DVAR; Sun and Crook, 1998) can also be used to assimilate radar observations with a much more balanced analysis, but it is computationally quite expensive in high-resolution storm-scale NWP.

The ARPS 3DVAR system has been successfully used in NOAA's "Hazardous Weather Testbed" spring forecast experiments (Clark et al., 2012b) for the past several years to analyze and detect convective-scale severe weather events (Gao et al., 2013; Calhoun et al., 2014; Smith et al., 2014). While the results from the 3DVAR-based deterministic forecasts are very encouraging and reveal the potential value of a convective-scale 3DVAR system, applying the 3DVAR approach to an ensemble system is crucial to quantify the large uncertainties associated with high-impact weather events. Using convective-scale ensembles and a cycled 3DVAR data assimilation system, Yussouf et al. (2013b) reported that an ensemble with multiphysics background fields provided more realistic probabilistic forecasts of the low-level rotation of an isolated tornadic supercell event (8 May 2003) than that with a fixed physics mesoscale background. To evaluate how well the system performs in forecasting a supercell outbreak with multiple storms and storm interactions, the tornadic supercell outbreak event that occurred on 24 May 2011 in Oklahoma, USA, was selected for investigation in the present study. A WRF model-based interface to the ARPS 3DVAR system was developed and used to assimilate radar observations into each member of a convective-scale ensemble system. The initial and boundary conditions were provided from a multiscale, multiphysics ensemble (Yussouf et al., 2013b). Five different data assimilation and forecasts experiments were conducted to evaluate the sensitivity of a convectivescale ensemble forecast system initialized with 3DVAR radar data assimilation. The experiments included two different data assimilation time frequencies $(5,10 \mathrm{~min})$, two in-cloud temperature adjustment schemes, and a fixed- and mixedmicrophysics ensemble, with the goal to determine which configuration works best for supercell forecasts in an ensemble framework.

A brief overview of the tornadic event is provided in section 2, followed by a description of the experimental design in section 3. The results of the analyses and forecasts are assessed in section 4 , and a final discussion provided in section 5 .

\section{Tornadic outbreak event}

On 24 May 2011, multiple violent tornadoes touched down across Oklahoma, causing extensive damage along their paths. An overview of the environmental conditions and the evolution of the convective storm for this severe weather outbreak event can be found in Fierro et al. (2012) and Jones et al. (2015). A total of 12 tornadoes were reported during the afternoon and evening hours (Table 1), and three of those were violent tornadoes with ratings on the enhanced Fujita (EF) scale of EF-4 or greater (Doswell et al., 2009) (Fig. 1a). Convective cells initiated in west-central Oklahoma along the dry line at 1900 UTC (Fig. 1b) and developed into several supercell thunderstorms that eventually moved into central Oklahoma during the next few hours, producing several

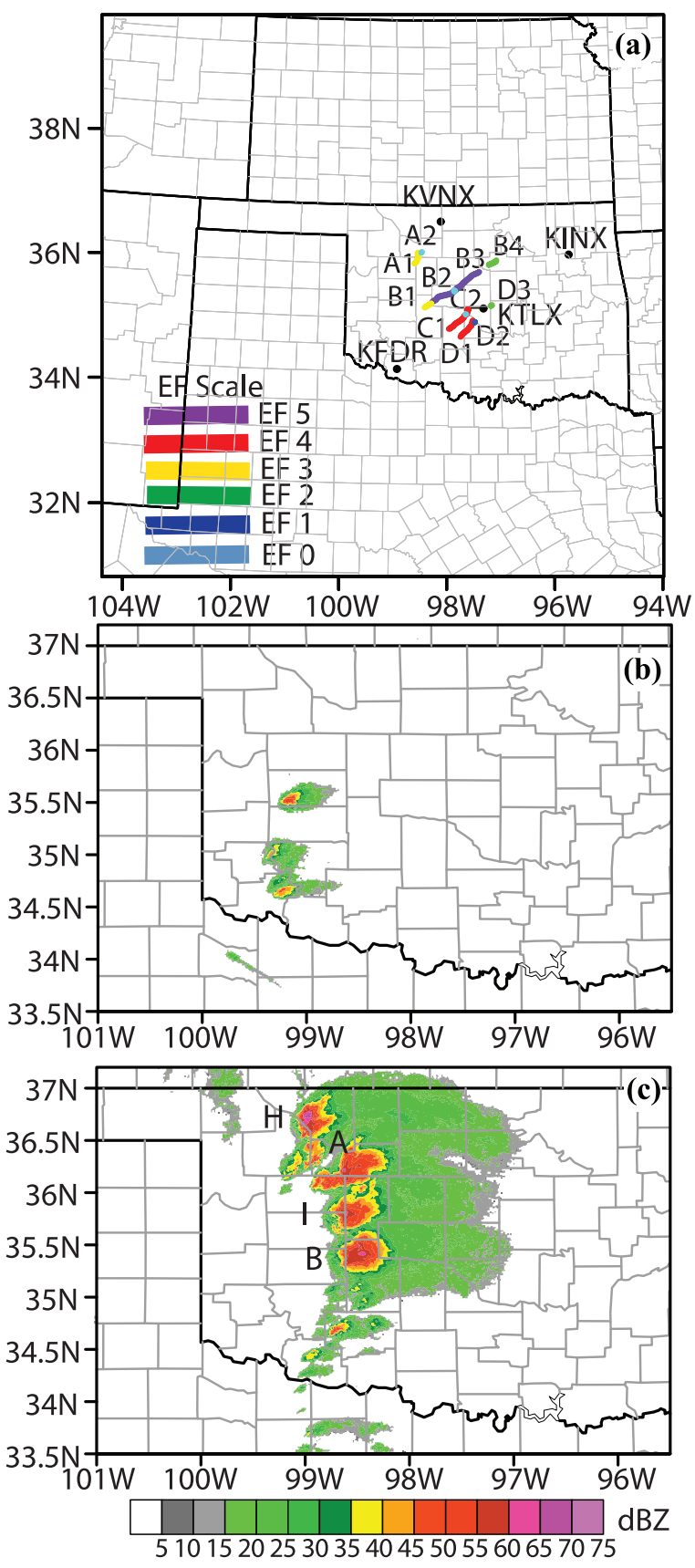

Fig. 1. (a) Storm-scale domain with WSR-88D locations (black dots) and NWS damage swaths (intensity ratings are indicated by colored lines) during the afternoon and evening hours. NSSL NMQ composite reflectivity (dBZ) observations valid at (b) 1900 UTC and (c) 2030 UTC 24 May 2011 over the region of interest. 
significant tornadoes. There were four supercell storms $(\mathrm{H}$, A, I, and B in Fig. 1c) ongoing at 2030 UTC. The first tornado (A1) was reported at around 2020 UTC at the position of supercell storm A and persisted until 2043 UTC (Table 1). The second tornado (B1), generated by supercell storm B, touched down at 2031 UTC and dissipated at 2046 UTC. Soon after, storm B produced the longest and most violent tornado (B2), which started at 2050 UTC and ended at 2235 UTC, having passed through Hinton, El Reno, Piedmont and Guthrie with a total path length of $101 \mathrm{~km}$, and rated at EF-5. The second most violent tornado (Tornado $\mathrm{C} 1$ ) traveled from Chickasha to Newcastle, a distance of $53.11 \mathrm{~km}$, and was rated at EF4. The third most violent tornado (Tornado D1) was an EF-4 tornado that passed through Bradley and Goldsby with a total path length of $37 \mathrm{~km}$, causing severe damage, killing 10 people, and injuring 290 people. Multiple operational Weather Surveillance Radar-1988 Doppler (WSR-88D) radars documented the life cycle of this tornado outbreak. These radars provide a unique dataset with which convective-scale analysis experiments could be conducted to assess the capability of the data assimilation and forecast system to predict low-level rotation within supercell storms.

\section{Data assimilation system and experimental design}

\subsection{Mesoscale ensembles}

A multiscale ensemble analysis and prediction system was employed in this study, based on the WRF-ARW model (Skamarock et al., 2008). The parent mesoscale model domain covered the contiguous United States with a horizontal grid resolution of $15 \mathrm{~km}$ and with a $3 \mathrm{~km}$ horizontal grid resolution convective-scale domain nested within the mesoscale domain covering Oklahoma and parts of the surrounding states (Fig. 1a). Both domains had 51 vertical grid levels from the surface up to $10 \mathrm{hPa}$. A 36-member ensemble was designed using the NCEP's three-hourly 21-member

Table 1. Tornado reports on 24 May 2011 in Oklahoma (http://www. srh.noaa.gov/oun/?n=events-20110524-tornadotable).

\begin{tabular}{|c|c|c|c|c|}
\hline $\begin{array}{c}\text { Event } \\
\text { Tornado ID }\end{array}$ & Time (UTC) & $\begin{array}{l}\text { Length of } \\
\text { path }(\mathrm{km})\end{array}$ & $\begin{array}{c}\mathrm{EF} \\
\text { rating }\end{array}$ & County \\
\hline A1 & 2020-2043 & 20.92 & EF-3 & $\begin{array}{l}\text { Dewey/Blaine/ } \\
\text { Major }\end{array}$ \\
\hline B1 & $2031-2046$ & 14.48 & EF-3 & Caddo \\
\hline A2 & 2047-2051 & 1.13 & EF-0 & Major \\
\hline B2 & 2050-2235 & 101.39 & EF-5 & $\begin{array}{l}\text { Canadian/King- } \\
\text { fisher/Logan }\end{array}$ \\
\hline B3 & $2137-2138$ & 2.41 & EF-0 & Canadian \\
\hline $\mathrm{C} 1$ & 2206-2301 & 53.11 & EF-4 & $\begin{array}{c}\text { Grady/McClain } \\
\text { Cleveland }\end{array}$ \\
\hline D1 & $2226-2305$ & 37.01 & EF-4 & Grady/McClain \\
\hline $\mathrm{C} 2$ & $2245-2246$ & 1.13 & EF-0 & McClain \\
\hline B4 & $2250-2305$ & 16.09 & EF-2 & Payne \\
\hline D2 & 2302 & 0.80 & EF-1 & McClain \\
\hline D3 & 2336-2339 & 3.22 & $\mathrm{EF}-2$ & Pottawatomie \\
\hline
\end{tabular}

GEFS (Toth et al., 2003; Wei et al., 2008). The first 18 of the 21 members were used to initialize a 36-member multiscale ensemble system at 0000 UTC 24 May 2011. Different combinations of physics schemes were applied to each member (Table 2) as the same design in Yussouf (2015) to address the uncertainties in model physics parameterization schemes (e.g., Stensrud et al., 2000, 2009; Fujita et al., 2007; Wheatley et al., 2012, Yussouf et al., 2013b). The same physics options for both the parent and nested grid ensembles were used in our experiments except that the cumulus parameterization scheme was turned off in the specific convective-scale experiments.

In order to obtain the background for mesoscale simulation, these data such as rawinsondes, marine, mesonet, metar, satellite-derived winds and aircraft from NOAA's Meteorological Assimilation Data Ingest System were assimilated every hour from 0100 UTC 24 May to 0000 UTC 25 May 2011 with the ensemble adjustment Kalman filter (Anderson, 2001) implemented in the Data Assimilation Research Testbed software system (Anderson and Collins, 2007; Anderson et al., 2009) using a configuration similar to that employed by Yussouf et al. (2013a, 2013b), Wheatley et al. (2014) and Jones et al. (2015). Radar observations were excluded to be assimilated in the mesoscale domain. Both 1way nested runs were conducted simultaneously in our setup. The boundary conditions of the nested storm-scale ensemble were provided by the parent mesoscale ensemble.

\subsection{DVAR scheme and cloud analysis system}

The data assimilation system used to assimilate radar velocity and reflectivity at the convective scale was the 3DVAR system with the WRF model (version 3.4.1) interface that includes a complex cloud analysis package (Gao et al., 2002, 2004; Brewster et al., 2005; Hu et al., 2006a). The system was computationally very efficient, and therefore relatively large model domains could be used on available computers to reduce the effects of lateral boundaries on the convective storms of interest (Stensrud and Gao, 2010). The 3DVAR system used a recursive filter (Purser et al., 2003a, 2003b) with a mass continuity equation and other constraints that were incorporated into a cost function, yielding 3D analyses of the wind components and other model variables. For accurately representing convective-scale storms, multiple analysis passes with different spatial scales of influence were applied in this system.

The cloud analysis package was initially developed using the Local Analysis and Prediction System (Albers et al., 1996), and then later applied to the ARPS system (Zhang et al., 1998; Brewster, 2002; Hu et al., 2006a). The cloud analysis package uses radar reflectivity and other cloud observational information to update several hydrometeor variables and potential temperature in the 3DVAR analysis step. One limitation of the cloud analysis package is that it does not update the number concentration variables from the doublemoment microphysics schemes, and therefore zeroes-out any update made in the analysis to the hydrometeor mixing ratios in the forecast step from the double-moment microphysics 
Table 2. Physics options for the multi-physics WRF mesoscale ensemble system.

\begin{tabular}{|c|c|c|c|c|c|c|c|}
\hline $\begin{array}{l}\text { Ensemble } \\
\text { member }\end{array}$ & $\begin{array}{l}\text { GEFS member } \\
\text { for IC and BC }\end{array}$ & $\begin{array}{c}\text { Cumulus } \\
\text { (15-km grid only) }\end{array}$ & Microphysics & PBL & $\begin{array}{l}\text { Land } \\
\text { surface }\end{array}$ & $\begin{array}{l}\mathrm{SW} \\
\text { radiation }\end{array}$ & $\begin{array}{l}\mathrm{LW} \\
\text { radiation }\end{array}$ \\
\hline 1 & 1 & Kain-Fritsch & Thompson & YSU & Noah & Dudhia & RRTM \\
\hline 2 & 2 & Kain-Fritsch & Thompson & YSU & Noah & RRTMG & RRTMG \\
\hline 3 & 3 & Kain-Fritsch & Thompson & MYJ & Noah & Dudhia & RRTM \\
\hline 4 & 4 & Kain-Fritsch & Thompson & MYJ & Noah & RRTMG & RRTMG \\
\hline 5 & 5 & Kain-Fritsch & Thompson & MYNN2 & Noah & Dudhia & RRTM \\
\hline 6 & 6 & Kain-Fritsch & Thompson & MYNN2 & Noah & RRTMG & RRTMG \\
\hline 7 & 7 & Grell-3 & Thompson & YSU & Noah & Dudhia & RRTM \\
\hline 8 & 8 & Grell-3 & Thompson & YSU & Noah & RRTMG & RRTMG \\
\hline 9 & 9 & Grell-3 & Thompson & MYJ & Noah & Dudhia & RRTM \\
\hline 10 & 10 & Grell-3 & Thompson & MYJ & Noah & RRTMG & RRTMG \\
\hline 11 & 11 & Grell-3 & Thompson & MYNN2 & Noah & Dudhia & RRTM \\
\hline 12 & 12 & Grell-3 & Thompson & MYNN2 & Noah & RRTMG & RRTMG \\
\hline 13 & 13 & Tiedke & Thompson & YSU & Noah & Dudhia & RRTM \\
\hline 14 & 14 & Tiedke & Thompson & YSU & Noah & RRTMG & RRTMG \\
\hline 15 & 15 & Tiedke & Thompson & MYJ & Noah & Dudhia & RRTM \\
\hline 16 & 16 & Tiedke & Thompson & MYJ & Noah & RRTMG & RRTMG \\
\hline 17 & 17 & Tiedke & Thompson & MYNN2 & Noah & Dudhia & RRTM \\
\hline 18 & 18 & Tiedke & Thompson & MYNN2 & Noah & RRTMG & RRTMG \\
\hline 19 & 18 & Kain-Fritsch & Thompson & YSU & Noah & Dudhia & RRTM \\
\hline 20 & 17 & Kain-Fritsch & Thompson & YSU & Noah & RRTMG & RRTMG \\
\hline 21 & 16 & Kain-Fritsch & Thompson & MYJ & Noah & Dudhia & RRTM \\
\hline 22 & 15 & Kain-Fritsch & Thompson & MYJ & Noah & RRTMG & RRTMG \\
\hline 23 & 14 & Kain-Fritsch & Thompson & MYNN2 & Noah & Dudhia & RRTM \\
\hline 24 & 13 & Kain-Fritsch & Thompson & MYNN2 & Noah & RRTMG & RRTMG \\
\hline 25 & 12 & Grell & Thompson & YSU & Noah & Dudhia & RRTM \\
\hline 26 & 11 & Grell & Thompson & YSU & Noah & RRTMG & RRTMG \\
\hline 27 & 10 & Grell & Thompson & MYJ & Noah & Dudhia & RRTM \\
\hline 28 & 9 & Grell & Thompson & MYJ & Noah & RRTMG & RRTMG \\
\hline 29 & 8 & Grell & Thompson & MYNN2 & Noah & Dudhia & RRTM \\
\hline 30 & 7 & Grell & Thompson & MYNN2 & Noah & RRTMG & RRTMG \\
\hline 31 & 6 & Tiedke & Thompson & YSU & Noah & Dudhia & RRTM \\
\hline 32 & 5 & Tiedke & Thompson & YSU & Noah & RRTMG & RRTMG \\
\hline 33 & 4 & Tiedke & Thompson & MYJ & Noah & Dudhia & RRTM \\
\hline 34 & 3 & Tiedke & Thompson & MYJ & Noah & RRTMG & RRTMG \\
\hline 35 & 2 & Tiedke & Thompson & MYNN2 & Noah & Dudhia & RRTM \\
\hline 36 & 1 & Tiedke & Thompson & MYNN2 & Noah & RRTMG & RRTMG \\
\hline
\end{tabular}

IC, initial condition; BC, boundary condition; PBL, planetary boundary layer; SW, shortwave; LW, longwave.

schemes. Future studies will address this limitation by using simple methods to diagnose these fields (e.g., see Dawson et al., 2015).

There are two different temperature adjustment schemes within the cloud analysis package: the latent heat adjustment scheme (LH) and the moist-adiabatic scheme (MA). The LH scheme adjusts the in-cloud temperature based on the latent heat release corresponding to the added cloud water and ice. The MA scheme calculates in-cloud temperature from the moist adiabatic temperature profile corresponding to an air parcel lifted from the low levels. The MA adjustment scheme is therefore more consistent with the physics of convective storms since it reflects the change in temperature in an ascending moist air parcel (Hu and Xue, 2007).

\subsection{Description of the assimilation experiments}

As mentioned earlier, the focus of this paper is to evaluate the convective-scale analyses and forecasts of the three tornadic supercells that occurred in central Oklahoma on 24 May 2011 using the 3DVAR data assimilation technique. The hourly updated 36 -member $15-\mathrm{km}$ mesoscale ensemble was used as the boundary conditions for the 3-km convective scale domain. Radial velocity and reflectivity observations from four operational WSR-88D radars over Oklahoma (Vance Air Force Base (KVNX), Tulsa (KINX), Oklahoma City (KTLX), and Frederick (KFDR)) were assimilated (Fig. 1a) using the 3DVAR technique and cloud analyses package.

The analysis variables in the 3DVAR system included the $U, V$ and $W$ components of wind, the potential temperature, pressure, and the water vapor mixing ratio. In addition, the potential temperature, rain, snow, and hail mixing ratios were adjusted using the cloud analysis package. Five different ensemble experiments were conducted (Table 3), with different combinations of assimilation frequency, in-cloud temperature adjustment schemes, and microphysics schemes. For the first four experiments, the same assimilation time win- 
dow of $30 \mathrm{~min}$, starting at 2000 UTC and ending at 2030 UTC, was used. In Exp10LH, radar observations were assimilated every 10 min using the LH in-cloud temperature adjustment scheme. In Exp5LH and Exp5MA, radar observations were assimilated every 5 min using the LH and MA in-cloud temperature adjustment schemes, respectively. These three experiments used the same Thompson microphysics scheme (Thompson et al., 2004). In Exp5MA_MP, the first 12 ensemble members used the semi-double moment Thompson microphysics scheme, the next 12 members used the Morrison double-moment scheme (Morrison et al., 2005), and the last 12 members used the WRF single-moment 6-class (WSM6) scheme (Hong et al., 2004; Hong and Lim, 2006). At the end of the 30-min data assimilation period, 1-hr ensemble forecasts were generated from the above four experiments (i.e., Exp10LH, Exp5LH, Exp5MA and Exp5MA_MP), starting at 2030 UTC and ending at 2130 UTC, which covered the lifetimes of tornadoes A2 and B1, and the partial lifetime of tornadoes A1 and B2 (Table 1). The last experiment, MultiExp, was similar to Exp5MA_MP, but instead of assimilating observations at 5-min intervals for 30 minutes, the assimilation window extended out to 2300 UTC for a total of 180 minutes and 1-h ensemble forecasts were generated from the analyses every $30 \mathrm{~min}$. MultiExp covered the lifetime of all the violent tornadoes over Oklahoma on 24 May 2011 (Table 1 and Fig. 2).

\section{Results}

The overall structure, location, and intensity of the supercell storms from the convective-scale reflectivity analyses and forecasts were compared against the National Mosaic and Multi-Sensor QPE (NMQ) 3D radar reflectivity mosaic (Zhang et al., 2011). The NMQ reflectivity was initially gridded using 1-km grid spacing, and thinned to a 3-km grid spacing to match the convective-scale WRF grid. In addition, the ETS, RMSE and bias of the convective-scale ensemble forecasts were calculated using the continuously cycled 3DVAR analyses produced by MultiExp.

\subsection{Impact of every 5-min and 10-min assimilation fre- quency}

The ensemble mean analyses for reflectivity and vertical vorticity at $5 \mathrm{~km}$ MSL from the 10-min and 5-min assimila-

Table 3. Information on the data assimilation (DA) and forecast configuration for each experiment, in-cloud temperature adjustment and microphysics scheme used.

\begin{tabular}{cccccc}
\hline $\begin{array}{c}\text { Experiment } \\
\text { name }\end{array}$ & $\begin{array}{c}\text { DA start-end } \\
\text { time (UTC) }\end{array}$ & $\begin{array}{c}\text { Forecast start-end } \\
\text { time (UTC) }\end{array}$ & $\begin{array}{c}\text { DA time window } \\
(\mathrm{min})\end{array}$ & $\begin{array}{c}\text { In-cloud temperature } \\
\text { adjustment }\end{array}$ & Microphysics \\
\hline Exp10LH & $2000-2030$ & $2030-2130$ & 10 & LH & Thompson \\
Exp5LH & $2000-2030$ & $2030-2130$ & 5 & LH & $\begin{array}{l}\text { Thompson } \\
\text { Thompson }\end{array}$ \\
Exp5MA & $2000-2030$ & $2030-2130$ & 5 & MA & O1: Members 1-12, Thompson \\
Exp5MA_MP & $2000-2030$ & $2030-2130$ & 5 & & O2: Members 13-24, Morrison \\
& & & & & O3: Members 25-36, WSM6 \\
MultiExp & $2000-2300$ & $2030-2130$ & 5 & & O1: Members 1-12, Thompson \\
& & $2100-2200$ & & & O2: Members 13-24, Morrison \\
& & $2130-2230$ & & & O3: Members 25-36, WSM6 \\
\end{tabular}

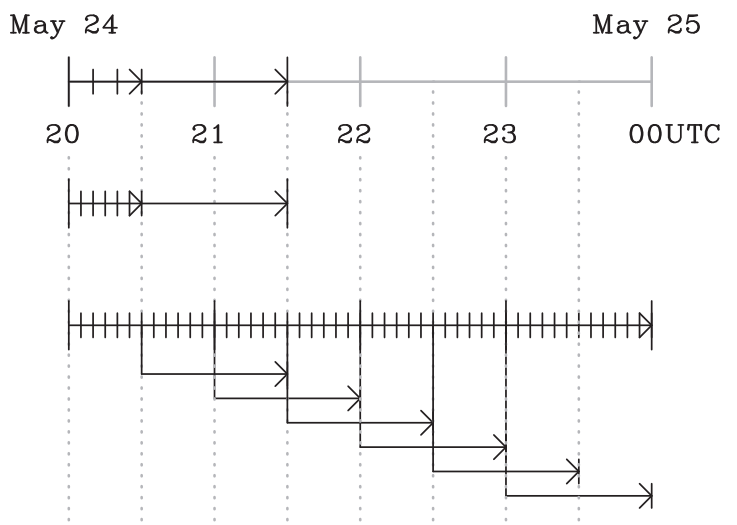

\author{
Exp10LH: Every 10-min 3DVAR \\ and $1-\mathrm{hr}$ forecasts \\ Exp5*: Every 5-min 3DVAR \\ and $1-\mathrm{hr}$ forecasts \\ MultiExp: Every 5-min 3DVAR \\ and $1-\mathrm{hr}$ forecasts
}

Fig. 2. Time lines for the storm-scale data assimilation and forecast experiments. Exp5* refers to Exp5LH, Exp5MA and Exp5MA_MP. 
tion frequencies are shown in Fig. 3. With only 30 mins of radar observation assimilation, both Exp10LH and Exp5LH were able to analyze the four ongoing supercells $(\mathrm{H}, \mathrm{A}, \mathrm{I}$, and B in Fig. 3e) reasonably well (Figs. 3a and c). The analysis reflectivity cores at 2030 UTC from both experiments had larger $\mathrm{dBZ}$ values than those from the observed cores. The analyzed vorticity for supercell A was along the NWS surveyed damage path of tornado A1 (which was ongoing at 2030 UTC), and the analyzed vorticity for supercell B was also collocated with the damage path of tornado B1 in both experiments. However, closer inspection revealed that the maximum vorticity at $5 \mathrm{~km}$ MSL in Exp5LH $\left(6.5 \times 10^{-3}\right.$ $\left.\mathrm{s}^{-1}\right)$ was larger than that in Exp10LH $\left(4.9 \times 10^{-3} \mathrm{~s}^{-1}\right)$. The vertical cross section (red line shown in Figs. 3a, c and e) from the 2030 UTC analysis indicated that the strong vertical vorticity was collocated with the high reflectivity columns in both Exp10LH and Exp5LH (Figs. 3b and d). However, the maximum vorticity along the vertical cross section in
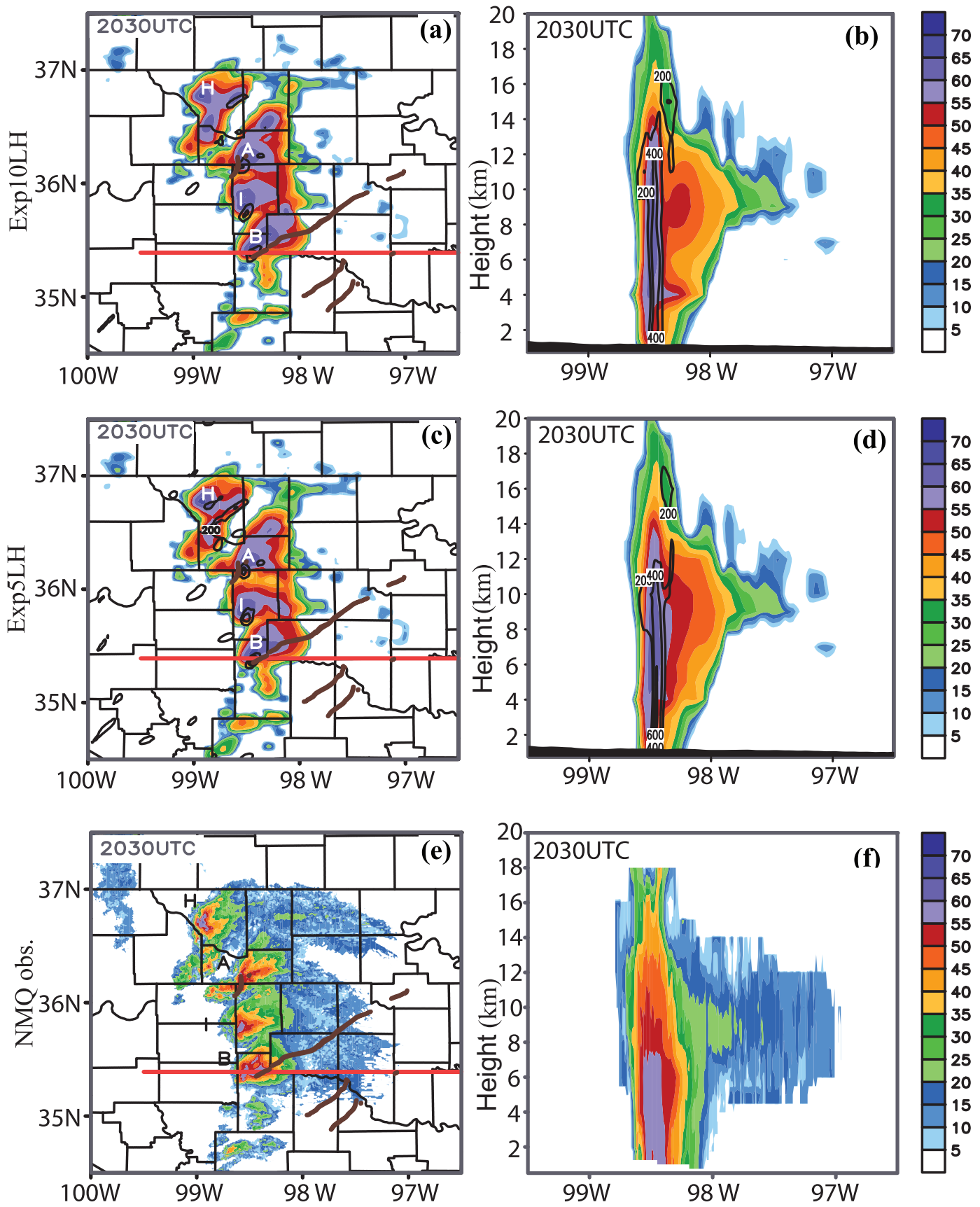

Fig. 3. Ensemble mean reflectivity (color scale; $5-\mathrm{dBZ}$ increments) and vertical vorticity (black contours; starting at $200 \times 10^{-5} \mathrm{~s}^{-1}$, with $200 \times 10^{-5} \mathrm{~s}^{-1}$ increments) analyses at $2030 \mathrm{UTC}$ from (a, b) Exp10LH and (c, d) Exp5LH. (e, f) NSSL NMQ reflectivity observations interpolated to the model grid. Panels (a, c, e) are the horizontal cross sections at $5 \mathrm{~km}$ MSL, while panels (b, d, f) are the vertical cross sections along the red lines in the $(\mathrm{a}, \mathrm{c}, \mathrm{e})$. 
Exp5LH $\left(6.44 \times 10^{-3} \mathrm{~s}^{-1}\right)$ was higher than that in Exp10LH $\left(5.30 \times 10^{-3} \mathrm{~s}^{-1}\right.$; Figs. $3 \mathrm{~b}$ and $\left.\mathrm{d}\right)$.

The 30-min ensemble mean reflectivity forecast (Figs. 4a and c) indicated that the supercells tended to move too fast northeastwards and generated higher $\mathrm{dBZ}$ values in the reflectivity core compared with the synthesized observed reflectivity (Fig. 4e). This was likely due to model error. In addition, storms A and I nearly merged with each other in both experiments, contrary to observations, and the vorticity slowly weakened in the model over the forecast period. The ensemble mean forecasts in Exp5LH generated higher vertical vorticity along the high reflectivity core (Fig. 4d) of supercell B compared to that in Exp10LH (Fig. 4b). However, the 30-min forecasts in Exp5LH and Exp10LH indicated that increasing the assimilation frequency from $10 \mathrm{~min}$ to $5 \mathrm{~min}$ in this study did not result in any obvious improvements in the forecasts.

\subsection{Comparison between the LH and MA in-cloud tem- perature adjustment schemes}

The ensemble mean reflectivity and vertical vorticity analyses at $5 \mathrm{~km}$ MSL from the two different in-cloud temperature adjustment schemes are shown in Fig. 5. While the reflectivity structure in both Exp5LH and Exp5MA were similar (Figs. 5a and c), the vertical vorticity analyses differed in magnitude. Exp5MA generated stronger circulations for all
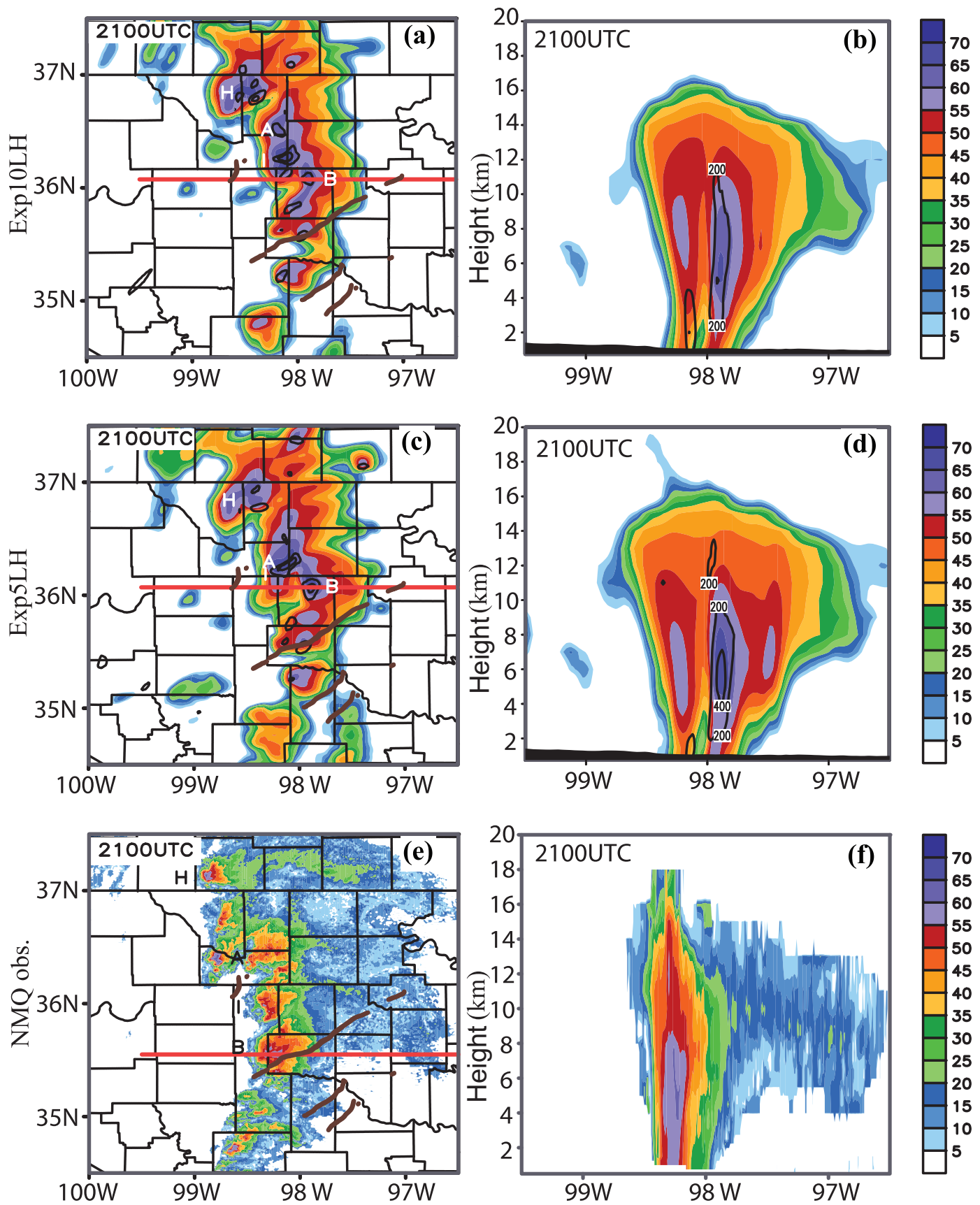

Fig. 4. As in Fig. 3 but for the 30-min ensemble mean forecasts valid at 2100 UTC. 
storm cells. The vertical vorticity centers collocated very well with the reflectivity core in both experiments (Figs. 5b and d).

The 20-min ensemble mean forecast valid at 2050 UTC is shown in Fig. 6. This was the time when storm B spawned tornado B2 (Fig. 1a). The forecast reflectivity field indicated that the supercells moved to the east and split into multiple cells (Fig. 6). Among these cells, strong mesocyclones associated with storm B existed in both Exp5LH and Exp5MA (Figs. 6a-d). Two reflectivity cores existed in experiment Exp5LH, which were caused by a new born cell, formed to the south of the supercell B (Figs. 6a and b). However, the 20-min forecast of Exp5MA associated with storm B looked more reasonable, with the vertical vorticity center embedded within the single reflectivity core (Figs. 6c and d). Overall, the results indicate that the moist adiabatic scheme generates more accurate dynamical fields than the latent heat adjustment scheme. This is probably due to the more realistic moist adiabatic adjustment scheme, as it reflects the temperature change in an ascending moist air parcel and heats the atmosphere through a greater depth compared with that in the latent heat scheme (Fig. 7). This agrees with the findings of another study, by Hu et al. (2006a).

\subsection{Quantitative comparison of the sensitivity experi- ments}

The ensemble spread of reflectivity at 3-km MSL in Exp5MA (dashed line) and Exp5MA_MP (solid line) dur- ing the $30-\mathrm{min}$ assimilation period are shown in Fig. 8 The mixed microphysics experiment, Exp5MA_MP, generated larger spread compared with the fixed microphysics experiment, Exp5MA. The larger ensemble spread from the mixed microphysics ensemble was due to the diversity in microphysics schemes across the mixed-microphysics ensemble members. The ensemble spread from Exp10LH, Exp5LH and Exp5MA was very similar (not shown).

During the first $20 \mathrm{~min}$ of the forecast period, the RMSEs for reflectivity in Exp5LH and Exp5MA were smaller than those in Exp10LH (Fig. 9a). Afterward, the RMSE and bias for reflectivity in Exp10LH were smaller than those in Exp5LH and Exp5MA. The differences in the RMSE for temperature variables between Exp5LH and Exp10LH were more than $1^{\circ} \mathrm{C}$, and the temperature bias in Exp5LH was smaller than that in Exp10LH (Fig. 9b). The RMSEs of the $U$ and $V$ components of wind in Exp5LH were slightly smaller than those in Exp10LH (Figs. 9c and d). Compared with the other experiments, Exp5MA_MP generated the smallest RMSE values (Fig. 9a) for the reflectivity field. In addition, the forecast of Exp5MA generated smaller RMSE and bias for the $U$ and $V$ components of wind than those of Exp5LH (Figs. 9c and d).

Overall, the results indicated that the data assimilation and forecast experiments with a 5-min assimilation frequency, MA in-cloud temperature adjustment scheme, and mixed-microphysics ensemble (Exp5MA_MP) generated
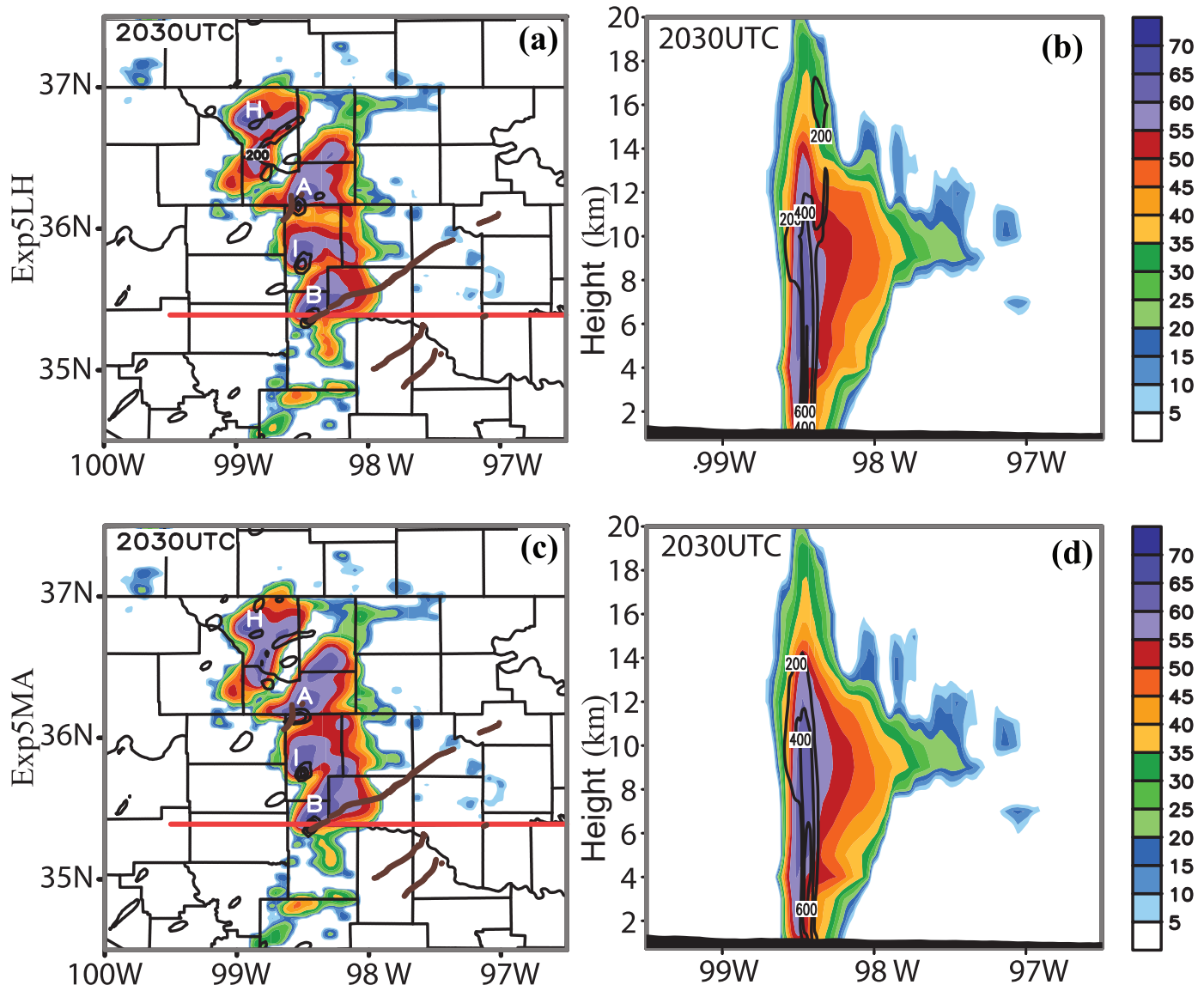

Fig. 5. As in Fig. 3 but for the ensemble mean analysis valid at 2030 UTC for (a, b) Exp5LH and (c, d) Exp5MA. 

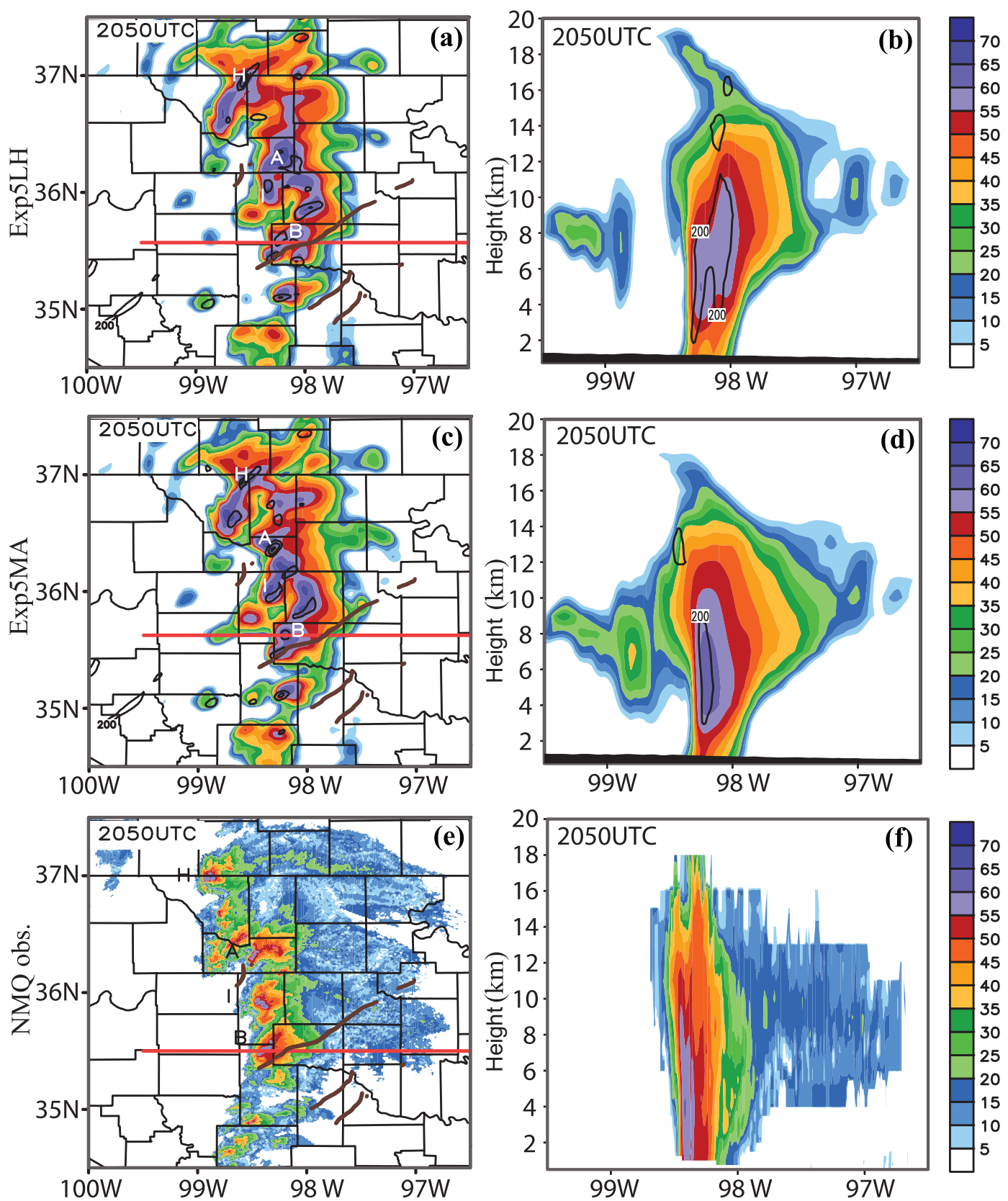

Fig. 6. As in Fig. 3 but for the 20-min ensemble mean forecast valid at 2050 UTC for (a, b) Exp5LH and (c, d) Exp5MA.

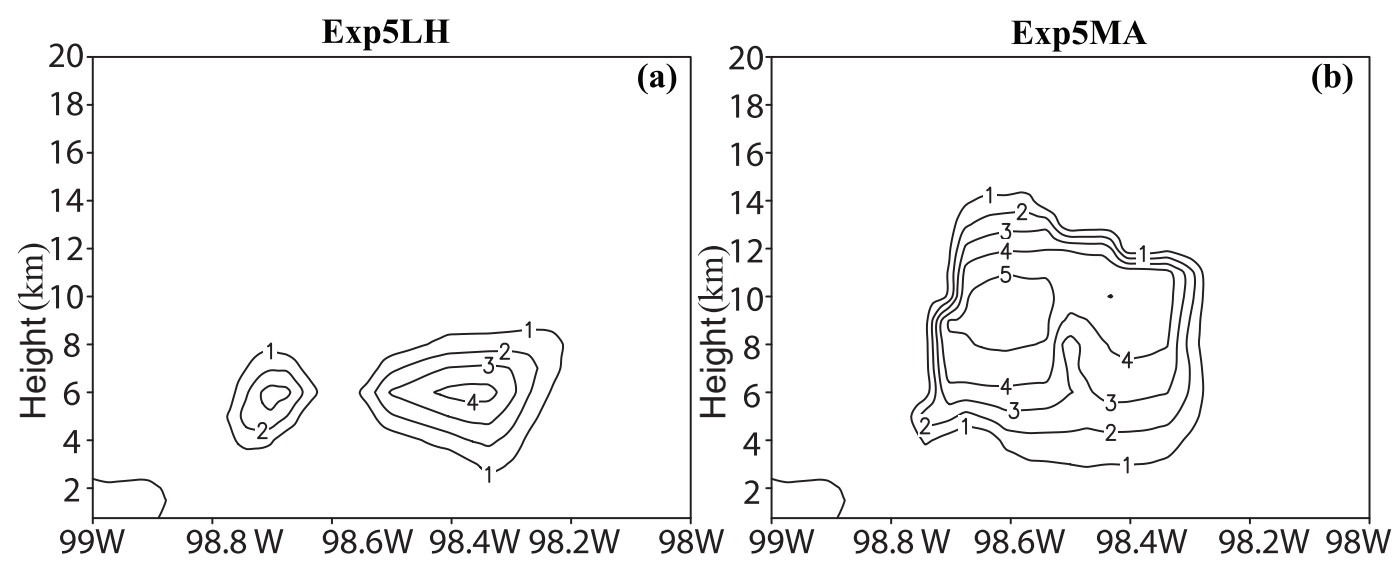

Fig. 7. Perturbation potential temperature (K) cross section through storm $B$ at the initial time 2000 UTC in (a) Exp5LH and (b) Exp5MA. These vertical cross sections are drawn along the center of storm B. 


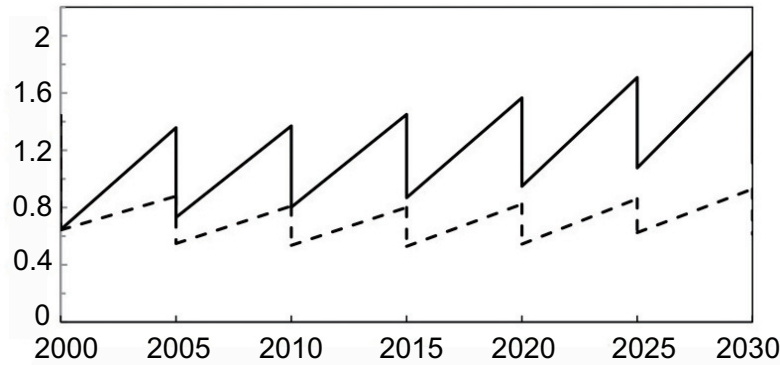

Fig. 8. Ensemble spread of reflectivity at $3 \mathrm{~km}$ MSL during the assimilation period from 2000 UTC to 2030 UTC for Exp5MA (dashed line) and Exp5MA_MP (solid line).

more accurate forecasts compared with the other three experiments. Thunderstorm simulations are known to be very sensitive to the microphysics parameterization scheme (Gilmore et al., 2004; van den Heever and Cotton, 2004; Snook and Xue, 2008), and one major source of error in storm-scale data assimilation and forecasts is the error introduced into the model from microphysics schemes. By using different microphysics schemes in the ensemble configurations, the different systematic errors associated with the microphysics schemes in the ensemble are diffused compared to that from the single model configuration. Thus, the better performance of Exp5MA_MP was likely due to a more accurate representation of model error associated with the microphysical parameterization schemes in the mixed-microphysics ensemble, which was consistent with the findings of Snook et al. (2012).

\subsection{Ensemble probabilistic forecasts of the vorticity of the supercell storms}

To evaluate how well the system performed in forecasting the rotation associated with the supercell outbreak, we continuously cycled the 5-min data assimilation system using the configuration of Exp5MA_MP for another 3-h period, and launched ensemble forecasts every $30 \mathrm{~min}$ from the cycled analyses (MultiExp). The ensemble probability of maximum vertical vorticity was calculated from this experiment.

The 3-km model horizontal grid spacing used in this study was far too coarse to explicitly resolve any tornado circulation, so we instead focused on mesocyclone forecasts. One measure that can be used to infer the amount of rotation within supercells is the vertical vorticity (Stensrud and Gao, 2010; Dawson et al., 2012; Yussouf et al., 2013a). To do so, the column maximum vertical vorticity between 0 and $5 \mathrm{~km}$ MSL at each model horizontal grid point was identified from the 36-member ensemble to calculate the ensemble probabil-
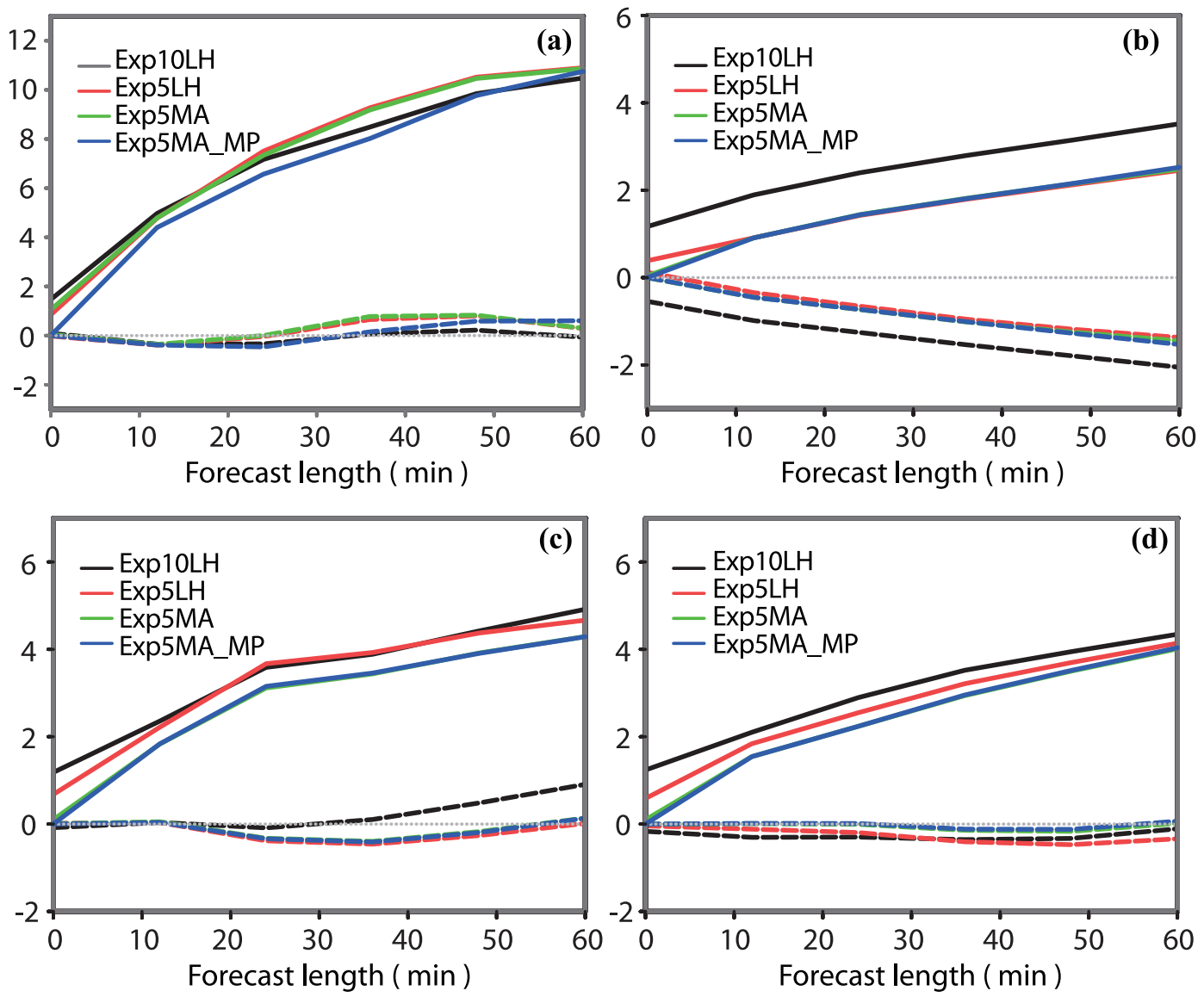

Fig. 9. One-hour forecast time series of RMSE (solid lines) and bias (dashed lines) for (a) reflectivity (dBZ), (b) temperature $\left({ }^{\circ} \mathrm{C}\right)$, (c) $U$-component wind $\left(\mathrm{m} \mathrm{s}^{-1}\right)$ and (d) $V$-component wind $\left(\mathrm{m} \mathrm{s}^{-1}\right)$ at $3 \mathrm{~km} \mathrm{MSL} \mathrm{in}$ Exp10LH (black lines), Exp5LH (red lines), Exp5MA (green lines) and Exp5MA_MP (blue lines). 

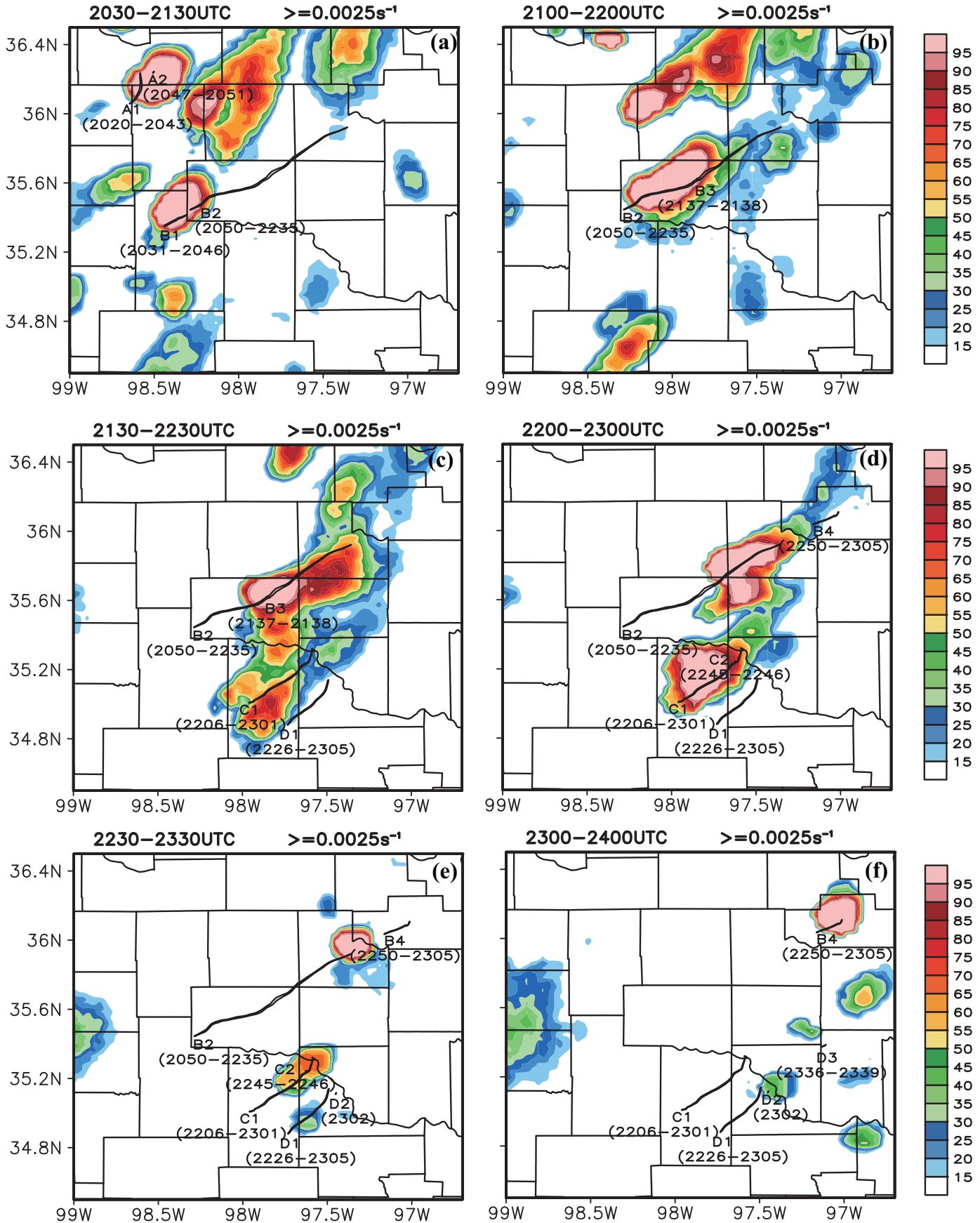

Fig. 10. One-hour neighborhood ensemble probability forecasts of column maximum vertical vorticity between 0 to $5 \mathrm{~km} \mathrm{MSL}$ at each horizontal grid point exceeding a threshold of $0.0025 \mathrm{~s}^{-1}$ within a radius of $9 \mathrm{~km}$ in MultiExp from every 30-min analysis valid at (a) 2030 UTC, (b) 2100 UTC, (c) 2130 UTC, (d) 2200 UTC, (e) 2230 UTC and (f) 2300 UTC. Overlain in each panel is the NWS surveyed tornado damage tracks (black outline) and the start and end times of observed tornado tracks.

ity of maximum vertical vorticity using thresholds of 0.0015 $\mathrm{s}^{-1}$ and $0.0025 \mathrm{~s}^{-1}$. The vertical depth of $0-5 \mathrm{~km}$ was chosen to account for both low-and mid-level rotation within the supercells. A neighborhood approach (Schwartz et al., 2010; Snook et al., 2012; Yussouf et al., 2013a) was used to calculate the ensemble probabilities, instead of using model horizontal grid point values to account for the mesocyclone position differences across the ensemble members. The forecasts at 5 min intervals were checked to determine whether the $0-5$ $\mathrm{km}$ maximum vertical vorticity exceeded the threshold within a horizontal radius of $9 \mathrm{~km}$ around a grid point. The ensemble probabilities were calculated as the percentage of ensemble members that met the criterion mentioned above. The 1-h ensemble probability forecasts of vertical vorticity exceeding a threshold of $0.0025 \mathrm{~s}^{-1}$ from MultiExp are shown in Fig. 10. A total of six 1-h ensemble forecasts were generated 


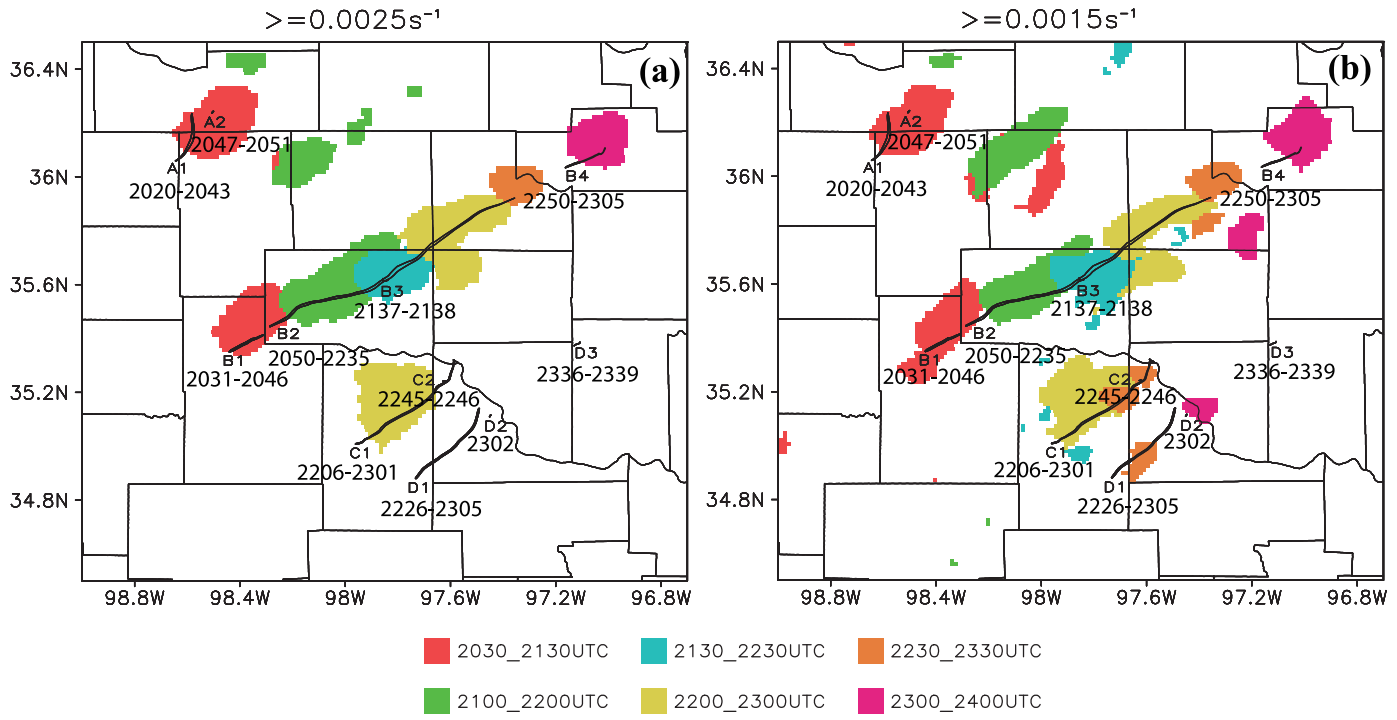

Fig. 11. One-hour neighborhood ensemble probability forecasts of vorticity between 0 and $5 \mathrm{~km}$ MSL, exceeding $90 \%$ for thresholds of (a) $0.0025 \mathrm{~s}^{-1}$ within a radius of $9 \mathrm{~km}$ and (b) $0.0015 \mathrm{~s}^{-1}$ within a radius of $6 \mathrm{~km}$ in MultiExp at every 30-min analysis interval. Overlain in each panel is the NWS surveyed tornado damage track (black outline) and the start and end times of violent observed tornado tracks.

from the analyses starting at 2030 UTC and at 30-min intervals thereafter. The last forecast was generated from the 2300 UTC analyses.

During this time period, around 11 tornadoes with ratings ranging from EF-0 to EF-5 occurred over Oklahoma (Table $1)$. The NWS-surveyed damage paths were overlaid on each panel only if that particular tornado was occurring during that forecast period. The forecasts from the 2030 UTC analyses generated a vorticity probability swath that overlapped the damage path of tornadoes A1, A2 and B1 with values above 95\% (Fig. 10a). The 1-h forecast vorticity swath beginning at 2100 UTC overlaid the damage path of tornado B2 (Fig. $10 \mathrm{~b})$. The forecast probabilities for tornado B3, which was briefly on the ground from 2137 to 2138 UTC, were around $90 \%$. There was another vorticity swath north of the B2-B3 track with $90 \%$ probabilities, and no damage path was associated with the swath. The vorticity swaths originating at 2130 UTC (Fig. 10c) aligned well with the damage paths of B3 and B2, with more than $90 \%$ probabilities earlier in the forecasts and above $70 \%$ later in the forecasts. The vorticity swaths for $\mathrm{C} 1$ were above $50 \%$. The forecast vorticity swaths beginning at 2200 UTC matched the time of the observed tornado tracks of $\mathrm{B} 2, \mathrm{C} 1$ and $\mathrm{C} 2$, and the probabilities were almost all above $90 \%$ (Fig. 10d). The forecast probabilities starting at 2230 UTC were above $15 \%-70 \%$ nearby the observed tornado tracks, except tornado B4. For the forecasts initiated at 2300 UTC, the probabilities of vorticity were above $95 \%$ for tornado B4, but no substantial probability of strong rotation was associated with tornado D3, which occurred at 2336 UTC.

The 1-h forecast probabilities with threshold values of $0.0025 \mathrm{~s}^{-1}$ and exceeding $90 \%$, generated from the every 30min analysis of MultiExp (Fig. 11a), covered the timing of the observed tornado tracks for most of the tornados, except
C2, D1, D2 and D3. Among those four tornadoes, C2 was rated EF-0, D2 was EF-1, D3 was EF-2, and only D1 was EF-4. This indicates that relatively weaker tornadoes may need lower threshold values to display the vorticity swaths. To the left (northwest) of the B tornado family, there was another model-generated high-probability rotation, but no tornado was associated with that forecast vorticity swath. The system was able to forecast vorticity swaths for those weaker (C2, D1 and D2) tornadoes with probabilities above $90 \%$ (Fig. 11b) when the vorticity threshold value was reduced to $0.0015 \mathrm{~s}^{-1}$. Further inspection revealed that the strength of the forecast vorticity swaths with thresholds lower than the values used in this study (i.e., $0.0025 \mathrm{~s}^{-1}$ and $0.0015 \mathrm{~s}^{-1}$ ) showed a gradual increase in probabilities for all storms, including the weaker tornadic storms (not shown). However, lowering the threshold value also increased the rotation area northwest of the B tornado family, where there were no tornadoes. Therefore, while decreasing the threshold value may increase the probability of rotation of weaker tornadoes, it may also increase the false alarm rate. Similar results also were reported by Yussouf et al. (2015). This indicates that, even using a 3-km grid resolution, the ensemble may be skillful in forecasting an individual storm's rotation intensity, but it also raises an important question on how to calibrate or differentiate between tornadic and non-tornadic supercells at grid resolutions that cannot explicitly resolve tornado-scale circulations. This question was outside the scope of the current study and remains open for future investigation.

\section{Summary and discussion}

In this study, several analysis and forecast experiments were conducted for the tornadic supercell storms that occurred on 24 May 2011 in Oklahoma, USA, using the ARPS 
3DVAR analysis system and WRF-ARW forecast model. A 36-member multiphysics, multiscale ensemble was used to provide the initial and boundary conditions for the ensemble 3DVAR analysis and forecast system. Radial velocity and reflectivity observations from four WSR-88D radars were assimilated into the convective-scale ensemble using the ensemble 3DVAR approach. Five different data assimilation and forecasts experiments were conducted at the convective scale to evaluate the sensitivity of the system to the observation assimilation time frequencies, in-cloud temperature adjustment schemes, fixed- and mixed-microphysics ensembles, and assimilation time window. The results indicated that the assimilation of radar observations with a 5-min frequency produced more accurate analyses and forecasts of temperature and $U$ and $V$ wind components than those with a 10min assimilation frequency. The ensemble forecasts from the moist adiabatic scheme (Exp5MA) generated more accurate dynamical fields than in the experiment with the latent heating scheme (Exp5LH), and the RMSEs for these fields were lower in Exp5MA. This was likely due to the more realistic representation of temperature adjustments of the ascending moist air parcel in the moist adiabatic adjustment scheme.

Overall, the results of the sensitivity experiments revealed that Exp5MA_MP performed better than the other experiments. This was likely due to the better representation of the microphysical errors in the mixed-microphysics ensemble. The composite neighborhood ensemble probabilistic forecasts of vertical vorticity with different threshold values indicated that the ensemble was able to forecast the rotation embedded in the supercells for most of the observed storms, and the vorticity swaths aligned well with the observed damage tracks with high probabilities. The overall encouraging results obtained from this study provide reasons for cautious optimism and motivate us to conduct further studies on how best to assimilate radar observations using an ensemble-based 3DVAR data assimilation and forecast system for NOAA's "Warn-on-Forecast" program.

Acknowledgements. Partial funding for this research was provided by the NOAA/Office of Oceanic and Atmospheric Research under the NOAA-University of Oklahoma Cooperative Agreement \#NA17RJ1227, the U.S. Department of Commerce and NSF AGS-1341878, the National Natural Science Foundation of China (Project No. 41305092), and the International S\&T Cooperation Program of China (ISTCP) (Grant No. 2011DFG23210). We thank our colleague Dr. Thomas JONES for proofreading the manuscript. Thanks also to Carrie LANGSTON for the NMQ reflectivity data. The computing for this project was performed at the University of Oklahoma (OU) Supercomputing Center for Education \& Research (OSCER). Local computer assistance was provided by Brett MORROW, Steven FLETCHER, Brad SWAGOWITZ, and Karen COOPER.

\section{REFERENCES}

Aksoy, A., D. C. Dowell, and C. Snyder, 2009: A multicase comparative assessment of the ensemble kalman filter for assim- ilation of radar observations. Part I: Storm-scale analyses. Mon. Wea. Rev., 137, 1805-1824.

Albers, S. C., J. A. McGinley, D. L. Birkenheuer, and J. R. Smart, 1996: The local analysis and prediction system (LAPS): Analyses of clouds, precipitation, and temperature. Wea. Forecasting, 11, 273-287.

Anderson, J. L., 2001: An ensemble adjustment Kalman filter for data assimilation. Mon. Wea. Rev., 129, 2884-2903.

Anderson, J. L., and N. Collins, 2007: Scalable implementations of ensemble filter algorithms for data assimilation. J. Atmos. Oceanic Technol., 24, 1452-1463.

Anderson, J. L., T. Hoar, K. Raeder, H. Liu, N. Collins, R. Torn, and A. Avellano, 2009: The data assimilation research testbed: A community facility. Bull. Amer. Meteor. Soc., 90, 1283-1296.

Brewster, K. A., 2002: Recent advances in diabatic initialization of a non-hydrostatic numerical model. Preprints, 15th Conf. on Numerical Weather Prediction/21st Conf. on Severe Local Storms, San Antonio, TX, Amer. Meteor. Soc., CD-ROM, J6.3. [Available online at http://arps.ou.edu/ARPS/ ARPS5DOC/BrewsterNWP2002.pdf.]

Brewster, K., M. Hu, M. Xue, and J. D. Gao, 2005: Efficient assimilation of radar data at high resolution for short-range numerical weather prediction. World Weather Research Program Symp. on Nowcasting and Very Short-Range Forecasting, WSN05, Toulouse, France, WMO World Weather Research Programme, Symp. CD, Paper 3.06.

Calhoun, K. M., T. M. Smith, D. M. Kingfield, J. D. Gao, and D. J. Stensrud, 2014: Forecaster use and evaluation of realtime 3DVAR analyses during severe thunderstorm and tornado warning operations in the hazardous weather testbed. Wea. Forecasting, 29, 601-613.

Clark, A. J., J. S. Kain, P. T. Marsh, J. Correia, M. Xue, and F. Y. Kong, 2012a: Forecasting tornado path lengths using a three-dimensional object identification algorithm applied to convection-allowing forecasts. Wea. Forecasting, 27, 10901113.

Clark, A. J., and Coauthors, 2012b: An overview of the 2010 hazardous weather testbed experimental forecast program spring experiment. Bull. Amer. Meteor. Soc., 93, 55-74.

Dawson, D. T., L. J. Wicker, E. R. Mansell, and R. L. Tanamachi, 2012: Impact of the environmental low-level wind profile on ensemble forecasts of the 4 May 2007 Greensburg, Kansas, tornadic storm and associated mesocyclones. Mon. Wea. Rev., 140, 696-716.

Dawson, D. T., M. Xue, J. A. Milbrandt, and A. Shapiro, 2015: Sensitivity of real-data simulations of the 3 May 1999 Oklahoma City tornadic supercell and associated tornadoes to multimoment microphysics. Part I: Storm-and tornado-scale numerical forecasts. Mon. Wea. Rev., 143, 2241-2265.

Doswell, C. A., III, H. E. Brooks, and N. Dotzek, 2009: On the implementation of the enhanced Fujita scale in the USA. Atmos. Res., 93, 554-563.

Dowell, D. C., F. Q. Zhang, L. J. Wicker, C. Snyder, and N. A. Crook, 2004: Wind and temperature retrievals in the 17 May 1981 Arcadia, Oklahoma, supercell: Ensemble kalman filter experiments. Mon. Wea. Rev., 132, 1982-2005.

Elmore, K. L., D. J. Stensrud, and K. C. Crawford, 2002: Explicit cloud-scale models for operational forecasts: A note of caution. Wea. Forecasting, 17, 873-884.

Fierro, A. O., E. R. Mansell, C. L. Ziegler, and D. R. MacGorman, 2012: Application of a lightning data assimilation tech- 
nique in the WRF-ARW model at cloud-resolving scales for the tornado outbreak of 24 May 2011. Mon. Wea. Rev., 140, 2609-2627.

Fujita, T., D. J. Stensrud, and D. C. Dowell, 2007: Surface data assimilation using an ensemble Kalman filter approach with initial condition and model physics uncertainties. Mon. Wea. Rev., 135, 1846-1868.

Gao, J. D., M. Xue, A. Shapiro, and K. K. Droegemeier, 1999: A variational method for the analysis of three-dimensional wind fields from two Doppler radars. Mon. Wea. Rev., 127, 21282142 .

Gao, J. D., M. Xue, K. Brewster, F. H. Carr, and K. K. Droegemeier, 2002: New development of a 3DVAR system for a non-hydrostatic NWP model. Preprints, 15th Conf. on $\mathrm{Nu}$ merical Weather Prediction/19th Conf. on Weather Analysis and Forecasting, San Antonio, TX, Amer. Meteor. Soc., 12.4.

Gao, J. D., M. Xue, K. Brewster, and K. K. Droegemeier, 2004: A three-dimensional variational data analysis method with recursive filter for Doppler radars. J. Atmos. Oceanic Technol., 21, 457-469.

Gao, J. D., and Coauthors, 2013: A real-time weather-adaptive 3DVAR analysis system for severe weather detections and warnings with automatic storm positioning capability. Wea. Forecasting, 28, 727-745.

Ge, G. Q., J. D. Gao, and M. Xue, 2013a: Impacts of assimilating measurements of different state variables with a simulated supercell storm and three-dimensional variational method. Mon. Wea. Rev., 141, 2759-2777.

Ge, G. Q., J. D. Gao, and M. Xue, 2013b: Impact of a diagnostic pressure equation constraint on tornadic supercell thunderstorm forecasts initialized using 3DVAR radar data assimilation. Advances in Meteorology, 2013, 947874.

Gilmore, M. S., J. M. Straka, and E. N. Rasmussen, 2004: Precipitation uncertainty due to variations in precipitation particle parameters within a simple microphysics scheme. Mon. Wea. Rev., 132, 2610-2627.

Hong, S. Y., and J. O. J. Lim, 2006: The WRF single moment 6 class microphysics scheme (WSM6). J. Korean Meteor. Soc., 42, 129-151.

Hong, S. Y., J. Dudhia, and S. H. Chen, 2004: A revised approach to ice microphysical processes for the bulk parameterization of clouds and precipitation. Mon. Wea. Rev., 132, 103-120.

$\mathrm{Hu}$, M., and M. Xue, 2007: Impact of configurations of rapid intermittent assimilation of WSR-88D radar data for the 8 May 2003 Oklahoma City tornadic thunderstorm case. Mon. Wea. Rev., 135, 507-525.

Hu, M., M. Xue, and K. Brewster, 2006a: 3DVAR and cloud analysis with WSR-88D level-II Data for the prediction of the fort worth, Texas, Tornadic Thunderstorms. Part I: Cloud analysis and its impact. Mon. Wea. Rev., 134, 675-698.

Hu, M., M. Xue, J. D. Gao, and K. Brewster, 2006b: 3DVAR and cloud analysis with WSR-88D Level-II Data for the prediction of the fort worth, Texas, Tornadic Thunderstorms. Part II: Impact of radial Velocity analysis via 3DVAR. Mon. Wea. Rev., 134, 699-721.

Jones, T. A., D. Stensrud, L. Wicker, P. Minnis, and R. Palikonda, 2015: Simultaneous radar and satellite data storm-scale assimilation using an ensemble Kalman filter approach for 24 May 2011. Mon. Wea. Rev., 143, 165-194.

Kain, J. S., and Coauthors, 2010: Assessing advances in the assimilation of radar data and other mesoscale observations within a collaborative forecasting-research environment. Wea. Fore- casting, 25, 1510-1521.

Lange, H., and G. C. Craig, 2014: The impact of data assimilation length scales on analysis and prediction of convective storms. Mon. Wea. Rev., 142, 3781-3808.

Morrison, H., J. A. Curry, and V. I. Khvorostyanov, 2005: A new double-moment microphysics parameterization for application in cloud and climate models. Part I: Description. J. Atmos. Sci., 62, 1665-1677.

Purser, R. J., W. S. Wu, D. F. Parrish, and N. M. Roberts, 2003a: Numerical aspects of the application of recursive filters to variational statistical analysis. Part I: Spatially homogeneous and isotropic Gaussian covariances. Mon. Wea. Rev., 131, $1524-1535$.

Purser, R. J., W. S. Wu, D. F. Parrish, and N. M. Roberts, 2003b: Numerical aspects of the application of recursive filters to variational statistical analysis. Part II: Spatially inhomogeneous and anisotropic general covariances. Mon. Wea. Rev., 131, 1536-1548.

Schwartz, C. S., and Coauthors, 2010: Toward improved convection-allowing ensembles: Model physics sensitivities and optimizing probabilistic guidance with small ensemble membership. Wea. Forecasting, 25, 263-280.

Skamarock, W. C., J. B. Klemp, J. Dudhia, D. O. Gill, D. Barker, M. G. Duda, X. Y. Huang, and W. Wang, 2008: A description of the advanced research WRF Version 3. NCAR Tech. Note TN-475+STR, 113 pp.

Smith T. M., and Coauthors, 2014: Examination of a real-time 3DVAR analysis system in the hazardous weather testbed. Wea. Forecasting, 29, 63-77.

Snook, N., and M. Xue, 2008: Effects of microphysical drop size distribution on tornadogenesis in supercell thunderstorms. Geophys. Res. Lett., 35, L24803, doi: 10.1029/2008 GL035866.

Snook, N., M. Xue, and Y. Jung, 2012: Ensemble probabilistic forecasts of a tornadic mesoscale convective system from ensemble kalman filter analyses using WSR-88D and CASA Radar Data. Mon. Wea. Rev., 140, 2126-2146.

Snyder, C., and F. Q. Zhang, 2003: Assimilation of simulated Doppler radar observations with an ensemble kalman filter. Mon. Wea. Rev., 131, 1663-1677.

Stensrud, D. J., and J. D. Gao, 2010: Importance of horizontally inhomogeneous environmental initial conditions to ensemble storm-scale radar data assimilation and very short-range forecasts. Mon. Wea. Rev., 138, 1250-1272.

Stensrud, D. J., J. W. Bao, and T. T. Warner, 2000: Using initial condition and model physics perturbations in short-range ensemble simulations of mesoscale convective systems. Mon. Wea. Rev., 128, 2077-2107.

Stensrud, D. J., and Coauthors, 2009: Convective-scale warn-onforecast system a vision for 2020. Bull. Amer. Meteor. Soc., 90, 1487-1499.

Stensrud, D. J., and Coauthors, 2013: Progress and challenges with warn-on-forecast. Atmos. Res., 123, 2-16.

Sun, J. Z., and N. A. Crook, 1998: Dynamical and microphysical retrieval from Doppler radar observations using a cloud model and its adjoint. Part II: Retrieval experiments of an observed Florida convective storm. J. Atmos. Sci., 55, 835-852.

Thompson, G., R. M. Rasmussen, and K. Manning, 2004: Explicit forecasts of winter precipitation using an improved bulk microphysics scheme. Part I: Description and sensitivity analysis. Mon. Wea. Rev., 132, 519-542.

Thompson, T. E., L. J. Wicker, X. G. Wang, and C. Potvin, 2015: 
A comparison between the local ensemble transform Kalman filter and the ensemble square root filter for the assimilation of radar data in convective-scale models. Quart. J. Roy. Meteor. Soc., 141, 1163-1176.

Tong, M. J., and M. Xue, 2005: Ensemble Kalman filter assimilation of Doppler radar data with a compressible nonhydrostatic model: OSS experiments. Mon. Wea. Rev., 133, 1789-1807.

Toth, Z., O. Talagrand, G. Candille, and Y. J. Zhu, 2003: Probability and ensemble forecasts. Forecast Verification: A Practitioner's Guide in Atmospheric Science, I. T. Jolliffe and D. B. Stephenson, Eds., John Wiley \& Sons Ltd., England, 137163.

van den Heever, S. C., and W. R. Cotton, 2004: The impact of hail size on simulated supercell storms. J. Atmos. Sci., 61, 15961609.

Wei, M. Z., Z. Toth, R. Wobus, and Y. J. Zhu, 2008: Initial perturbations based on the ensemble transform (ET) technique in the NCEP global operational forecast system. Tellus A, $\mathbf{6 0}$, 62-79.

Wheatley, D. M., D. J. Stensrud, D. C. Dowell, and N. Yussouf, 2012: Application of a WRF mesoscale data assimilation system to springtime severe weather events 2007-09. Mon. Wea. Rev., 140, 1539-1557.

Wheatley, D. M., N. Yussouf, and D. J. Stensrud, 2014: Ensemble kalman filter analyses and forecasts of a severe mesoscale convective system using different choices of microphysics schemes. Mon. Wea. Rev., 142, 3243-3263.

Xue, M., and Coauthors, 2011: Realtime convection-permitting ensemble and convection-resolving deterministic forecasts of CAPS for the hazardous weather testbed 2010 spring experiment. Proc. 25th Conference on Wea. Forecasting, 20th Conference on Numerical Weather Prediction, Amer. Meteor. Soc., Seattle, WA.

Yussouf, N., E. R. Mansell, L. J. Wicker, D. M. Wheatley, and D. J. Stensrud, 2013a: The ensemble kalman filter analyses and forecasts of the 8 May 2003 Oklahoma City tornadic supercell storm using single-and double-moment microphysics schemes. Mon. Wea. Rev., 141, 3388-3412.

Yussouf, N., J. D. Gao, D. J. Stensrud, and G. Q. Ge, 2013b: The impact of mesoscale environmental uncertainty on the prediction of a tornadic supercell storm using ensemble data assimilation approach. Advances in Meteorology, 2013, 731647.

Yussouf, N., D. C. Dowell, L. J. Wicker, K. H. Knopfmeier, and D. M. Wheatley, 2015: Storm-scale data assimilation and ensemble forecasts for the 27 April 2011 severe weather outbreak in Alabama. Mon. Wea. Rev., 143, 3044-3066.

Zhang, J., F. Carr, and K. Brewster, 1998: ADAS cloud analysis. Preprints, 12th Conf. on Numerical Weather Prediction, Phoenix, AZ, Amer. Meteor. Soc., 185-188.

Zhang, F., C. Snyder, and J. Z. Sun, 2004: Impacts of initial estimate and observation availability on convective-scale data assimilation with an ensemble kalman filter. Mon. Wea. Rev., 132, 1238-1253.

Zhang, J., and Coauthors, 2011: National mosaic and multi-sensor QPE (NMQ) system: Description, results, and future plans. Bull. Amer. Meteor. Soc., 92, 1321-1338. 